\title{
Replication of Marburg Virus in Human Endothelial Cells A Possible Mechanism for the Development of Viral Hemorrhagic Disease
}

\author{
Hans-Joachim Schnittler, ${ }^{*}$ Friederike Mahner, ${ }^{*}$ Detlev Drenckhahn, ${ }^{*}$ Hans-Dieter Klenk, ${ }^{*}$ and Heinz Feldmann ${ }^{*}$ \\ *Institut für Virologie, Philipps-Universität Marburg, 3550 Marburg, Germany; \\ ${ }^{\ddagger}$ Institut für Anatomie, Universität Würzburg, 8700 Würzburg, Germany
}

\begin{abstract}
Marburg and Ebola virus, members of the family Filoviridae, cause a severe hemorrhagic disease in humans and primates. The disease is characterized as a pantropic virus infection often resulting in a fulminating shock associated with hemorrhage, and death. All known histological and pathophysiological parameters of the disease are not sufficient to explain the devastating symptoms. Previous studies suggested a nonspecific destruction of the endothelium as a possible mechanism. Concerning the important regulatory functions of the endothelium (blood pressure, antithrombogenicity, homeostasis ), we examined Marburg virus replication in primary cultures of human endothelial cells and organ cultures of human umbilical cord veins. We show here that Marburg virus replicates in endothelial cells almost as well as in monkey kidney cells commonly used for virus propagation. Our data support the concept that the destruction of endothelial cells resulting from Marburg virus replication is a possible mechanism responsible for the hemorrhagic disease and the shock syndrome typical of this infection. (J. Clin. Invest. 1993. 91:1301-1309.) Key words: filoviridae • hemorrhagic fever • shock syndrome • human umbilical cord vein • endothelium
\end{abstract}

\section{Introduction}

Infections with filoviruses often cause a fulminating hemorrhagic disease with a severe shock syndrome and high mortality in humans and in rhesus monkeys $(1,2)$. The family Filoviridae (3) consists of Marburg virus (MBG), ${ }^{1}$ the two related subtypes of Ebola virus (EBO), and a recently isolated Ebolalike virus, called Reston virus (RES) $(4,5)$. MBG, the prototype filovirus, was first isolated in 1967 following human outbreaks of acute hemorrhagic fever in Germany and Yugoslavia (6). Since that time, sporadic, virologically confirmed MBG diseases occurred in various parts of Africa (7-9).

Filoviruses constitute the third family of nonsegmented, negative-strand RNA viruses, beside the Paramyxoviridae and

Address correspondence and reprint requests to Heinz Feldmann, Special Pathogens Branch, Division of Viral and Rickettsial Diseases, National Center for Infectious Disease Control, 1600 Clifton Road, Mailstop G14, Atlanta, GA 30333.

Received for publication 26 June 1992 and in revised form 5 November 1992.

1. Abbreviations used in this paper: DIC, disseminated intravascular coagulation; EBO, Ebola virus; HUVEC, human umbilical vein endothelial cells; MBG, Marburg virus; RES, Reston virus.

J. Clin. Invest.

(c) The American Society for Clinical Investigation, Inc. 0021-9738/93/04/1301/09 \$2.00

Volume 91, April 1993, 1301-1309
Rhabdoviridae, within the new proposed order Mononegavirales (10). Virions are composed of a helical nucleocapsid surrounded by a lipid envelope. The genome is nonsegmented, of negative sense, and $19 \mathrm{~kb}$ in length $(3,11,12)$. Virion particles contain at least seven structural proteins $(8,13-16)$.

Filovirus infections have several pathological features in common with other severe viral hemorrhagic fevers such as Lassa fever, hemorrhagic fever with renal syndrome, and Dengue hemorrhagic fever (5). Among these viruses, filoviruses cause the highest case-fatality rates ( 35\% for MBG [6] and up to $90 \%$ for EBO, subtype Zaire [17]) and the most severe hemorrhagic manifestations. The pathophysiologic events that make filovirus infections of humans so devastating are still obscure. The viruses are pantropic, but no single organ shows sufficient damage to account for either the onset of the severe shock syndrome or the bleeding tendency (18).

Endothelial cells form the inner surface of blood vessels and play a key role in regulation of blood pressure, homeostasis, and antithrombogenicity. These cells form a selective barrier controlling the exchange of small solutes and macromolecules between the blood and the interstitial fluid of tissues. Increased vascular permeability observed during acute inflammation and shock symptomatic of response to various endogenous and exogenous mediators follows a paracellular pathway (19-22). Endothelial cell lysis is observed in the development of shock lung often associated with a disseminated intravascular coagulation (DIC) $(23,24)$. A comparable shock syndrome is also observed in MBG disease, and it has been speculated that this is caused either by destruction of endothelial cells following viral replication or by unspecific immune response and oxidant injury (25). However, no direct experimental evidence has been obtained for either mechanism.

To determine whether dysfunction and damage of endothelial cells can be caused by filovirus infection, we examined the replication of MBG in primary cultures of human umbilical vein endothelial cells (HUVEC) and organ culture of human umbilical veins. Data presented in this report demonstrate that the virus replicates in both systems and suggest that damage of the endothelial cell during filovirus infection can be caused primarily by virus replication.

\section{Methods}

Virus and cell line. The Musoke strain of MBG isolated in Kenya in 1980 (9) was used for the studies. Virus was grown in E6 cells, a cloned line of Vero cells (CRL 1586; American Type Culture Collection, Rockville, MD).

Preparation of primary endothelial cell cultures. HUVEC were collected according to the previously described method (22). Washed umbilical cord veins were filled with collagenase $(0.05 \%)$ from Clostridium histolyticum (Sigma Immunochemicals, St. Louis, MO) for 5 min at $37^{\circ} \mathrm{C}$. The collected cells were washed twice in Medium 199 (Gibco, Eggenstein, Germany) supplemented with $20 \%$ pooled human serum 
from healthy donors (tested negative for antibodies to Marburg virus), $25 \mathrm{U} / \mathrm{ml}$ penicillin $\mathrm{G}$ (Sigma Immunochemicals), and $25 \mu \mathrm{g} / \mathrm{ml} \mathrm{strep-}$ tomycin sulfate (Sigma Immunochemicals) and subsequently cultured until confluency. Cells were seeded on glass coverslips for immunofluorescence and on polycarbonate filters (Falcon Labware, Oxnard, CA) for electron microscopy. Both tissue culture carriers were coated with cross-linked gelatin from porcine skin as follows: Coverslips were incubated with $0.5 \%$ gelatin for $2 \mathrm{~h}$. Subsequently $2 \%$ glutaraldehyde diluted in PBS ( $\mathrm{pH} 7.4$ ) were used to cross-link gelatine for 30 min. Coverslips were sterilized with $70 \%$ ethanol for $1 \mathrm{~h}$ and extensively washed in PBS before use.

Organ culture of human umbilical veins. Postpartum human umbilical cord veins were washed immediately in Medium 199, and veins were prepared carefully to preserve the integrity of the endothelial cell surface. $1-\mathrm{cm}$ pieces of the opened vein were incubated in Medium 199 supplemented with $20 \%$ human serum, $25 \mathrm{U} / \mathrm{ml}$ penicillin $\mathrm{G}$ and 25 $\mu \mathrm{g} / \mathrm{ml}$ streptomycin sulfate at $37^{\circ} \mathrm{C}$. Prior to infection cryostat sections were stained with $1 \%$ toluidine blue to evaluate histological features of the tissue and to examine the integrity of the endothelial cells.

Antisera. Immunofluorescence was performed using either a reconvalescence serum from a person recovered from MBG hemorrhagic disease (26) or an experimental guinea pig serum directed against SDSinactivated MBG.

Mode of virus infection. Almost confluent monolayers and pieces of umbilical cord veins (prepared as described above) were infected with MBG at a multiplicity of infection (m.o.i.) of $10^{-2}$ plaque-forming units per cell (p.f.u./cell). Adsorption of the virus was performed at $37^{\circ} \mathrm{C}$ for $30 \mathrm{~min}$. Subsequently, the inoculum was removed, cells were washed twice with PBS, and the appropriate media were added (E6 cells: Dulbecco medium containing $2 \%$ fetal calf serum (FCS); HUVEC: Medium 199 containing 20\% human serum). Infected cells were incubated for the appropriate time at $37^{\circ} \mathrm{C}(14,15)$.

Plaque assay. Confluent monolayers of E6 cells (cultured in six well tissue culture plates, Greiner, Frickenhausen, Germany) were infected with MBG propagated in E6 cells and HUVEC at dilutions ranging from $10^{-1}$ to $10^{-8}$. Dilutions were prepared in Dulbecco medium without FCS. Following an adsorption period of $30 \mathrm{~min}$ at $37^{\circ} \mathrm{C}$, cells were washed three times with PBS. The infected cells were overlayed with Dulbecco medium containing $0.6 \%$ low-gelling temperature agarose derived from agar (FMC Corp., Rockland, ME) and 2\% FCS. Plates were kept for $20 \mathrm{~min}$ at $4^{\circ} \mathrm{C}$ for solidification of the overlay and then incubated at $37^{\circ} \mathrm{C}$ for $8 \mathrm{~d}$. For cell fixation, agar was overlayed with a solution containing $0.2 \%$ crystal violet, $2 \%$ ethanol, and $4 \%$ formalin, and kept overnight at room temperature. Agar was removed, and fixed monolayers were washed several times with $\mathrm{H}_{2} \mathrm{O}$ and airdried.

Immunofluorescence. Endothelial cells and E6 cells cultured on glass coverslips were infected with virus at a m.o.i. of $10^{-2}$ p.f.u./cell. Following appropriate incubation times, cells were fixed with $2 \%$ formaldehyde in PBS for $10 \mathrm{~min}$, washed in PBS, permeabilized in $100 \%$ acetone $\left(-20^{\circ} \mathrm{C}\right)$ for $1 \mathrm{~min}$, and washed twice in PBS. The monolayers were incubated with the appropriate antiserum (described above) followed by the corresponding secondary antibody labeled with tetramethyl rhodamine isothiocyanate (TRITC); (Sigma Immunochemicals) each for $1 \mathrm{~h}$ at room temperature. Antibodies directed to von Willebrand factor were purchased from Sigma Immunochemicals.

Transmission electron microscopy. Monolayers of cells grown on polycarbonate filters were fixed in $2 \%$ glutaraldehyde. After a wash with PBS, monolayers were postfixed with $1 \% \mathrm{OsO}_{4}$ in distilled water for $1 \mathrm{~h}$. Dehydration was performed in a graded series of ethanol. A mixture of propylene oxide and epoxy resin (1:1) (Epon-812; Serva, Heidelberg, Germany) was used for immersion. Final embedding in Epon- 812 was done by standard procedure at $65^{\circ} \mathrm{C}$ for $12 \mathrm{~h}$. Ultrathin sections were stained with uranyl acetate and lead citrate. Sections were observed and photographed in a Zeiss E 109 electron microscope.

$R N A$ polymerase chain reaction (PCR). Tissue culture supernatants were clarified by centrifugation at $6.000 \mathrm{~g}$ for $15 \mathrm{~min}$ at $4^{\circ} \mathrm{C}$ (Heraeus, Minifuge T). For viral genomic RNA (vRNA) isolation 1 ml of clarified supernatant was digested with proteinase $\mathrm{K}$ at a concentration of $50 \mu \mathrm{g} / \mathrm{ml}$ in $0.5 \%$ SDS for $1 \mathrm{~h}$ at $37^{\circ} \mathrm{C}$, extracted once with an equal volume of phenol, once with phenol/chloroform ( $\mathrm{vol} / \mathrm{vol})$ (1:1), and twice with chloroform. RNA was precipitated by adding 0.1 volume of sodium acetate ( $\mathrm{pH} 5.2$ ) and 2.5 volume of ethanol $\left(-20^{\circ} \mathrm{C}\right)$ at $-70^{\circ} \mathrm{C}$ overnight, washed twice with $70 \%$ ethanol, dried and resuspended in $20 \mu \mathrm{l} \mathrm{H}_{2} \mathrm{O}$ containing $1 \mathrm{U} / \mu$ l of ribonuclease inhibitor (RNasin; Boehringer, Mannheim, Germany). RNA PCR was performed with two synthesized oligonucleotides containing BamHI recognition sites (underlined) at their 5' ends: 5'-GACGGATCCACTTTTATAGCCCACCACATTGTGTGA-3' (downstream located primer, complementary to the viral genomic RNA; L gene, position 22322258 , [15]) and 5'-GACGGATCCTCATAGAGTTGTTATACATTGATTATC-3' [upstream located primer, identical to the viral genomic RNA; L gene, position 2449-2423, (15)]. $1 \mu \mathrm{l}$ vRNA and $1.5 \mu \mathrm{M}$ "downstream" primer were mixed and incubated at $80^{\circ} \mathrm{C}$ for $3 \mathrm{~min}$ and at room temperature for $30 \mathrm{~min}$. The reverse transcriptase reaction (1. cDNA strand synthesis) and the following amplification were performed as described previously $(11,15)$.

Southern blotting. cDNA products were analyzed on $1.5 \%(\mathrm{wt} / \mathrm{vol})$ agarose gels. Southern blotting was performed as described (27) using nylon membranes (Amersham, Braúnschweig, Germany). For hybridization a cDNA clone, containing a part of the L gene ORF (4407 nucleotides; position 186-4593 [15]), ligated into the in vitro transcription vector (pGEM3Zf; Promega Biotec, Madison, WI) downstream of the bacteriophage T7 RNA polymerase promotor, was used to produce ${ }^{35} \mathrm{~S}-\alpha \mathrm{ATP}$-labeled run-off transcripts. These transcripts were hybridized under stringent conditions $\left(50 \%\right.$ formamide, $\left.42^{\circ} \mathrm{C}\right)$ to the blotted cDNA products, and signals were visualized by fluorography.

\section{Results}

Replication in primary cultures of human endothelial cells. In a first series of experiments we investigated MBG replication in cultured human endothelial cells by phase contrast microscopy and immunofluorescence technique. Primary cultures of human endothelial cells seeded on glass coverslips were infected with MBG at a m.o.i. of $10^{-2}$ p.f.u./cell. Following various incubation times (1-6 d), infected monolayers showed an increased cytopathogenic effect (c.p.e.) beginning $4 \mathrm{~d}$ after infection (data not shown). $3 \mathrm{~d}$ after infection staining of the monolayer with an antibody directed to MBG revealed an immunofluorescence pattern showing dots of various size in infected endothelial cells (Fig. $1 a$ ). The endothelial location of MBGcaused immunostaining was further confirmed by double immunofluorescence using an antibody directed to von Willebrand factor, which is known to be a marker for endothelial cells of various locations and species in vitro and in situ (28) (Fig. $1 \mathrm{~b}$ ). Immunofluorescence of MBG-infected E6 cells at various times postinfection showed a different pattern with the main fluorescence located at the cell margins (Fig. 1 c). This observation is in accordance with the extended intracellular spaces of infected E6 cells caused by extensive virus budding from the lateral membrane (Fig. $2 c$ ).

For electron microscopic investigations primary cultures of endothelial cells were grown on polycarbonate filters and infected with MBG at a m.o.i. of $10^{-2}$ p.f.u./cell. Filters were fixed and processed for electronmicroscopy at various times postinfection. Investigated monolayers contained numerous Weibel Palade bodies, which represent the intracellular storage site of von Willebrand factor (29) (Fig. $4 a$ ). Virus budding occurred preferentially from the apical surface of cultured endothelial cells within the first $3 \mathrm{~d}$ postinfection (Fig. $2 a$ ). How- 

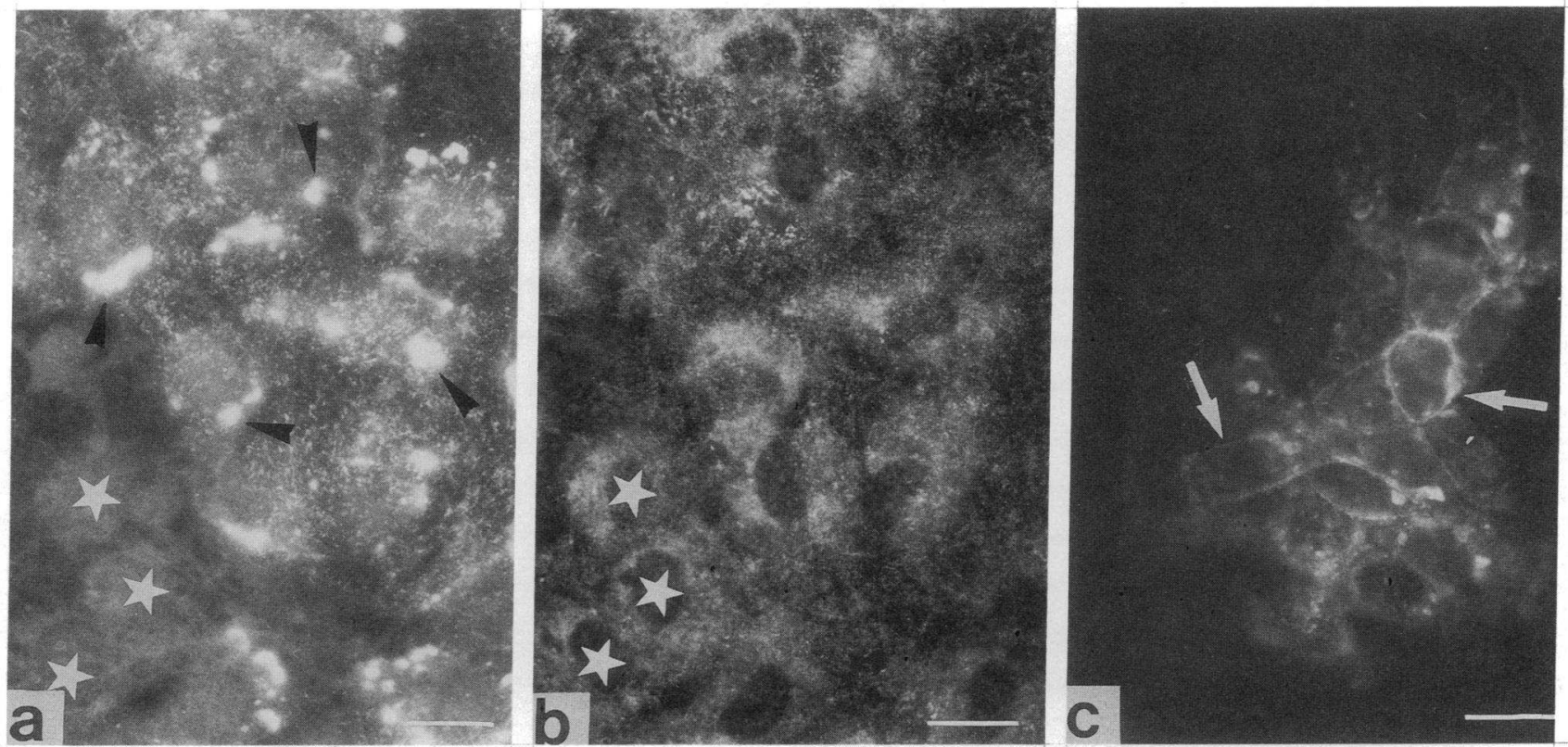

Figure 1. Immunofluorescence of cultured human endothelial $(a, b)$ and E6 cell monolayers $(c)$ infected with Marburg virus. Infected endothelial monolayers were stained by double labeling with an antibody directed to total MBG proteins $(a)$ and to von-Willebrand factor $(b)$ to identify infected endothelial cells. As seen in $a$, infected endothelial cells show a punctuated fluorescence as well as intensely fluorescent patches (arrowheads), whereas uninfected cells show only a background staining (data not shown) identical to those indicated by asterisks. Labeling of exactly the same cells with an antibody directed to von-Willebrand factor revealed a homogeneous distribution of von-Willebrand antigen within all cells $(b)$. A different pattern of immunofluorescence was seen in E6 cells using a reconvalescence serum from a person recovered from MBG disease $(c)$. The fluorescence is prominent primarily at the cell borders (arrows). Bars, $20 \mu \mathrm{m}$.

ever rarely, budding of virus could also be observed at the basal side and even within the cell-cell junctions of the endothelium. After prolonged incubation, a loss of the preferred vectorial virus budding was observed, resulting in a randomized budding from the cell membrane (Fig. $2 b$ ). In E6 cells, on the other hand, budding of MBG occurred even early in infection in a randomized fashion along the entire plasma membrane without any vectorial release of virion particles (Fig. $2 c$ ).

Budding of the mature filamentous virions seemed to occur preferentially in a vertical mode from the plasma membrane. Plasma membranes appeared thickened where virus budding occurred, which might be caused by an incorporation of viral proteins (Fig. $3 a$ ). Budding in a horizontal mode could not be observed. Virion particles appeared in multiple forms (e.g., annular, 6-shaped, U-shaped, filamentous) (Fig. 3) as described previously for propagation in other cells (30). Spikes were clearly visible on the surface of virus particles (Fig. $3 a$ ). In infected endothelial cells two types of cytoplasmic inclusions could be observed (Fig. 4). One type appeared as multilamellar inclusions (Fig. $4 \mathrm{~b}$ ) similar to those found only in infected Vero cells but without showing the heavily stained strands in the periphery (30). The second type of inclusions consists of electron-dense filamentous material (Fig. $4 a$ ). Both types of inclusion bodies probably consist of viral nucleocapsids that accumulate in the cytoplasm. These cytoplasmic accumulations of viral proteins cause the intense patchy immunostaining seen in several of the infected cells (Fig. 1).

To demonstrate that HUVEC-derived MBG is infectious, we performed plaque assays on E6 cells from culture supernatants of infected endothelial cells harvested 8-144 h postinfection. For comparison, we also determined infectious virus released from E6 cells, the standard cell line used for MBG-propa- gation. Virus was first detectable $48 \mathrm{~h}$ after infection (titer: $10^{1}$ p.f.u./ml). At $6 \mathrm{~d}$ postinfection virus titers reached a maximum of $10^{7}$ p.f.u./ml, which is nearly identical to virus titers usually obtained from E6 cells (Fig. $5 a$ ). The plaque morphology of both HUVEC and E6 cell-propagated virus did not significantly differ (data not shown). These findings demonstrate that human endothelial cells are permissive for MBG.

In a second assay we performed RNA PCR of infected HUVEC supernatants to determine the earliest time of virus release and thus the length of the viral replication cycle. RNA PCR was performed using a set of primers located within the $L$ gene of MBG amplifying a cDNA product of 236 nucleotides containing two DdeI recognition sites (15). As shown in Figures $5 b$ and $c$, RNA PCR first resulted in positive cDNA products $12 \mathrm{~h}$ postinfection. cDNA products were not detectable within the first $8 \mathrm{~h}$ postinfection. The specificity of the amplified products was considered by two independent approaches: (a) Southern blot analysis using a ${ }^{35} \mathrm{~S}-\alpha \mathrm{ATP}$-labeled run-off transcript of 4407 nucleotides of the L gene (Fig. $5 c$ ), and (b) the pattern of fragments obtained after digestion with the restriction endonuclease DdeI (data not shown). Spectrophotometric analysis of precipitated PCR samples revealed a continuous increase of cDNA products from 12 to $144 \mathrm{~h}$ postinfection. These results confirm the infectivity of the budded virus and further indicate a replication cycle for MBG of approximately $12 \mathrm{~h}$ in HUVEC.

Replication in organ culture of human umbilical cord vein. We have also analyzed virus replication in organ cultures derived from human umbilical cord veins using essentially the same procedures as with endothelial tissue cultures. In this system the endothelial cells still rest on a basement membrane and were not manipulated by proteases like collagenase or trypsin 

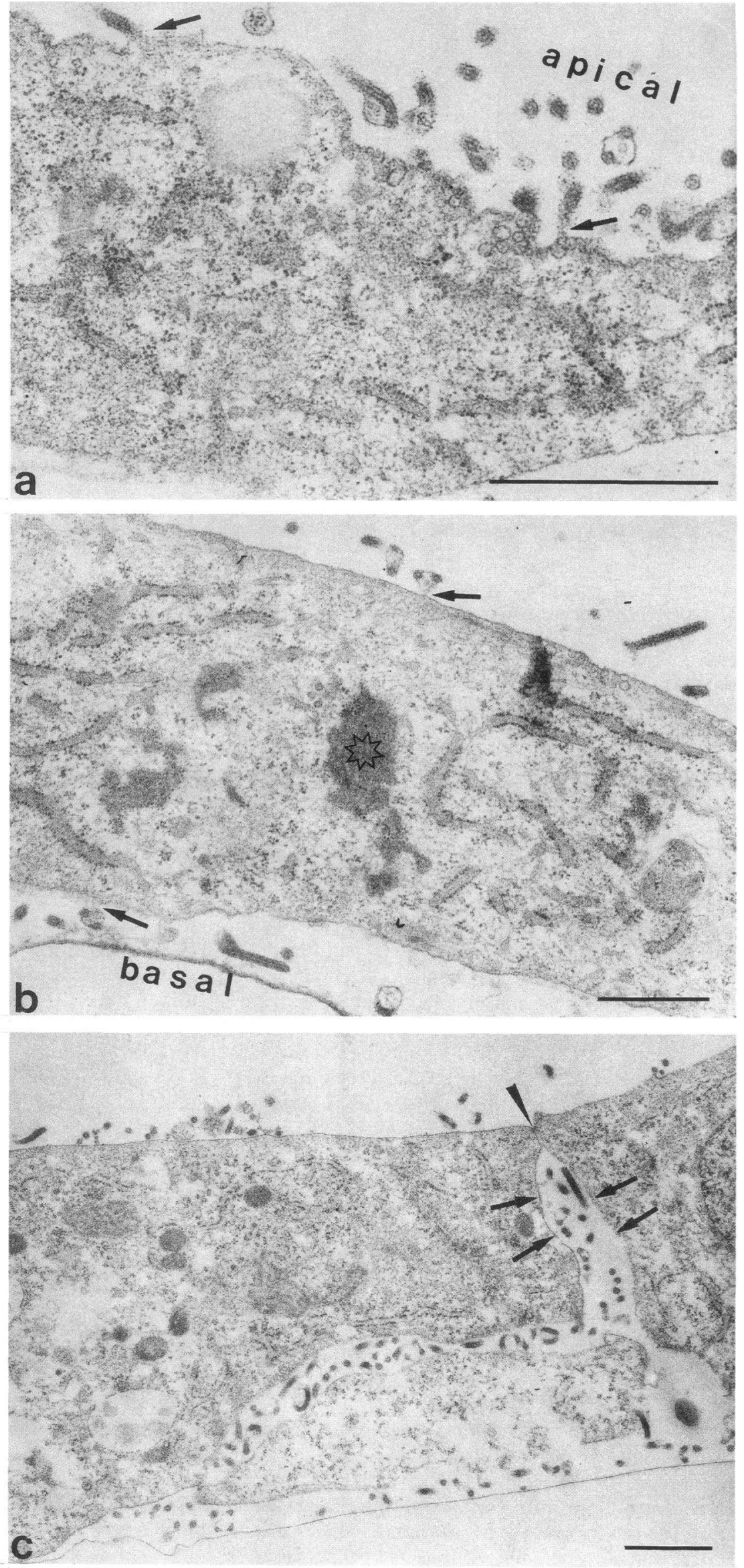

Figure 2. Transmission electron microscopy of cultures of human endothelial cells and of E6 cells infected with Marburg virus. Virus budding ( $a$ and $b$, arrows) in endothelial cells $3 \mathrm{~d}$ postinfection occurred preferentially from the apical membrane $(a)$ whereas $5 \mathrm{~d}$ postinfection a more randomized budding could be observed $(b)$. The asterisk in $(b)$ indicates a viral inclusion body probably consisting of nucleocapsides. Virus budding in E6 cells occurred randomly even early in infection ( $3 \mathrm{~d}$ postinfection) (c). The intercellular space is extended by extensive virus budding from the lateral membrane ( $c$, arrows). Junctions are indicated by an arrowhead. Bars, $0.5 \mu \mathrm{m}$. 


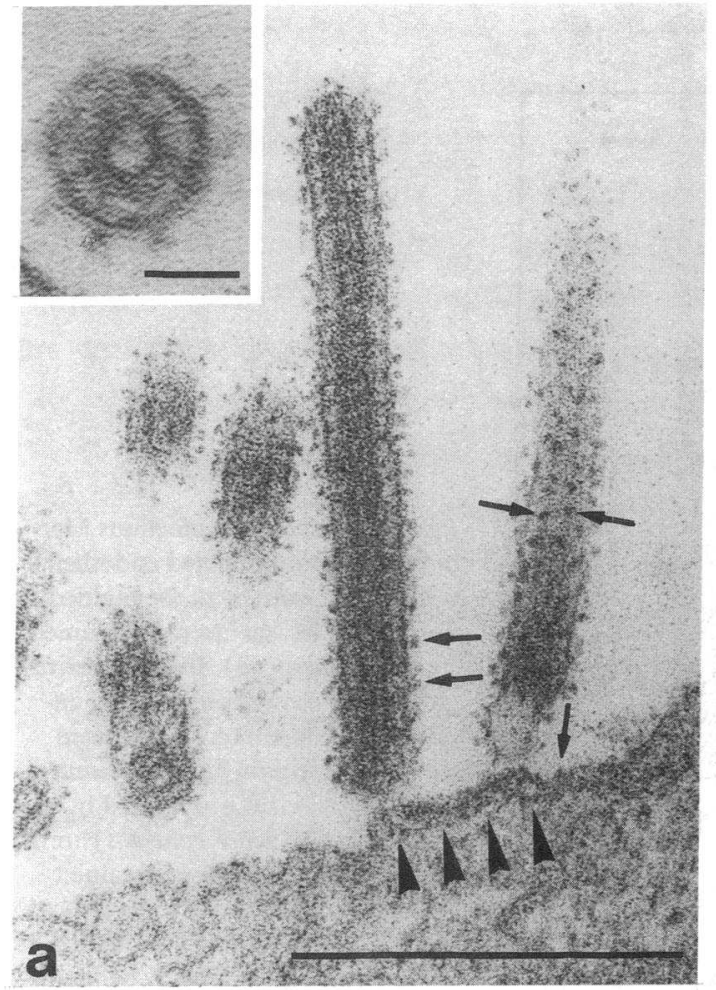

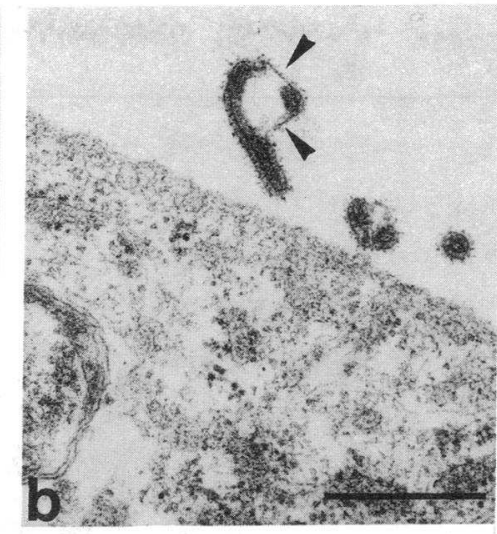

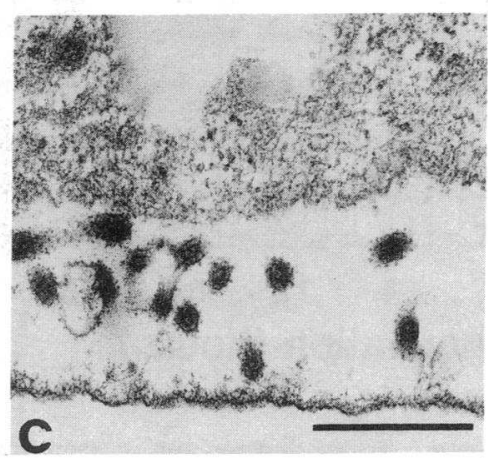

Figure 3. Virus budding in cultured human endothelial cells. Virus particles originated in endothelial cells do not differ morphologically from virus propagated in E6 cells. Particles consist of a central channel surrounded by the nucleocapsid $(a$, inset $)$. The nucleocapsid is further surrounded by a membrane envelope in which spikes are inserted ( $a$, arrows). The plasma membrane of the endothelial cell is thickened at locations where virus budding occurs ( $a$, arrowheads). Virion particles budding from the apical $(b)$ as well as the basolateral plasmamembrane of endothelial cells $(c)$ show a broad variety of multiple forms (long filamentous, sometimes branched forms; $\mathrm{U}(6)$-shaped forms [ $b$, arrowheads] circular forms). Bars, $0.5 \mu \mathrm{m}$; Bar inset, $50 \mathrm{~nm}$.
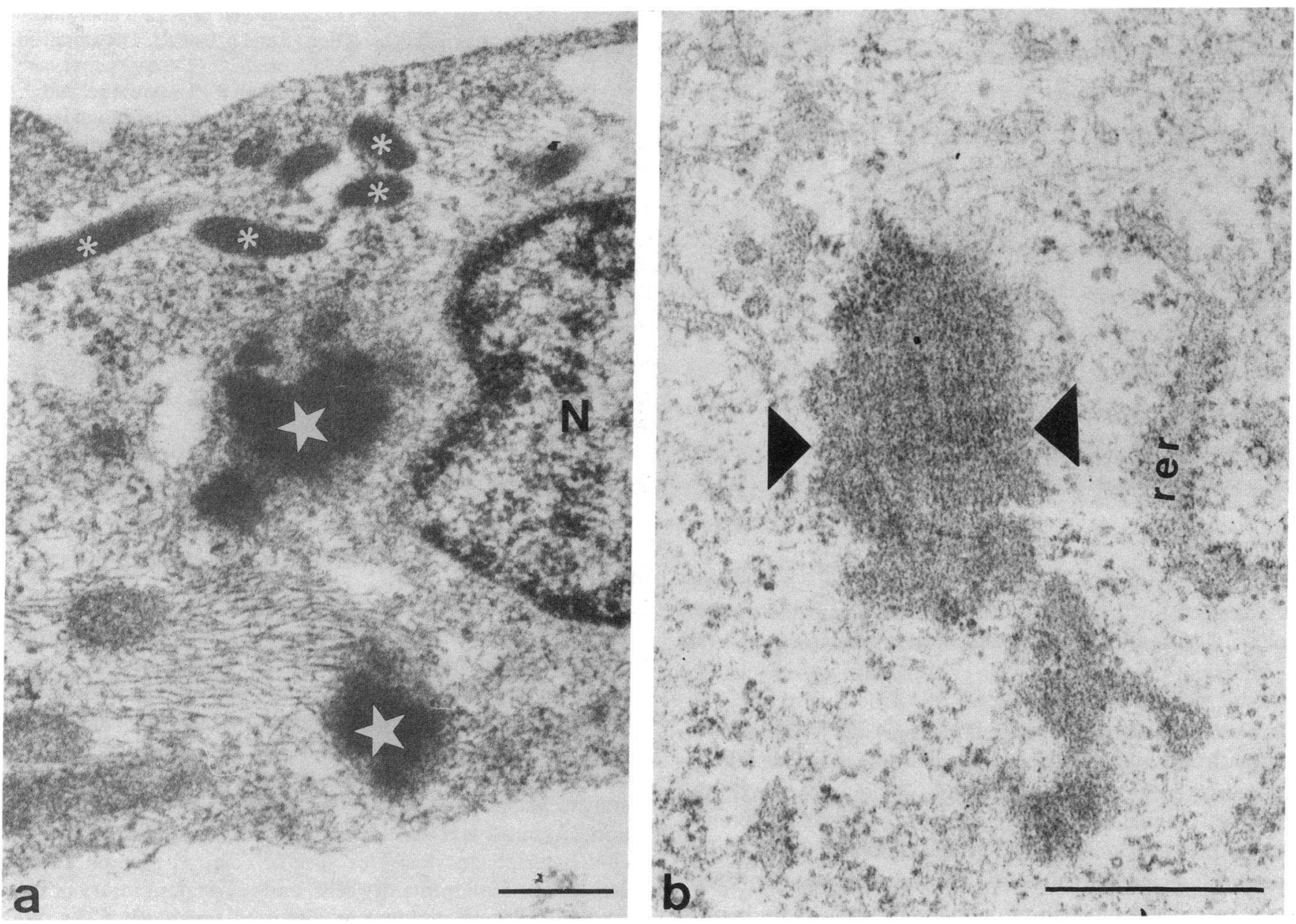

Figure 4. Two forms of viral inclusions in infected cultured human endothelial cells. Viral inclusions are found in the cytoplasm of infected endothelial cells in two forms. Dark extended homogeneous inclusions ( $a$, big asterisks) and lamellae inclusions ( $b$, big arrowheads). Weibel palade bodies ( $a$, small asterisks) can be seen identifying the cells as endothelium. $\mathrm{N}$, nucleus; rer, rough endoplasmic reticulum. Bars, $0.5 \mu \mathrm{m}$. 


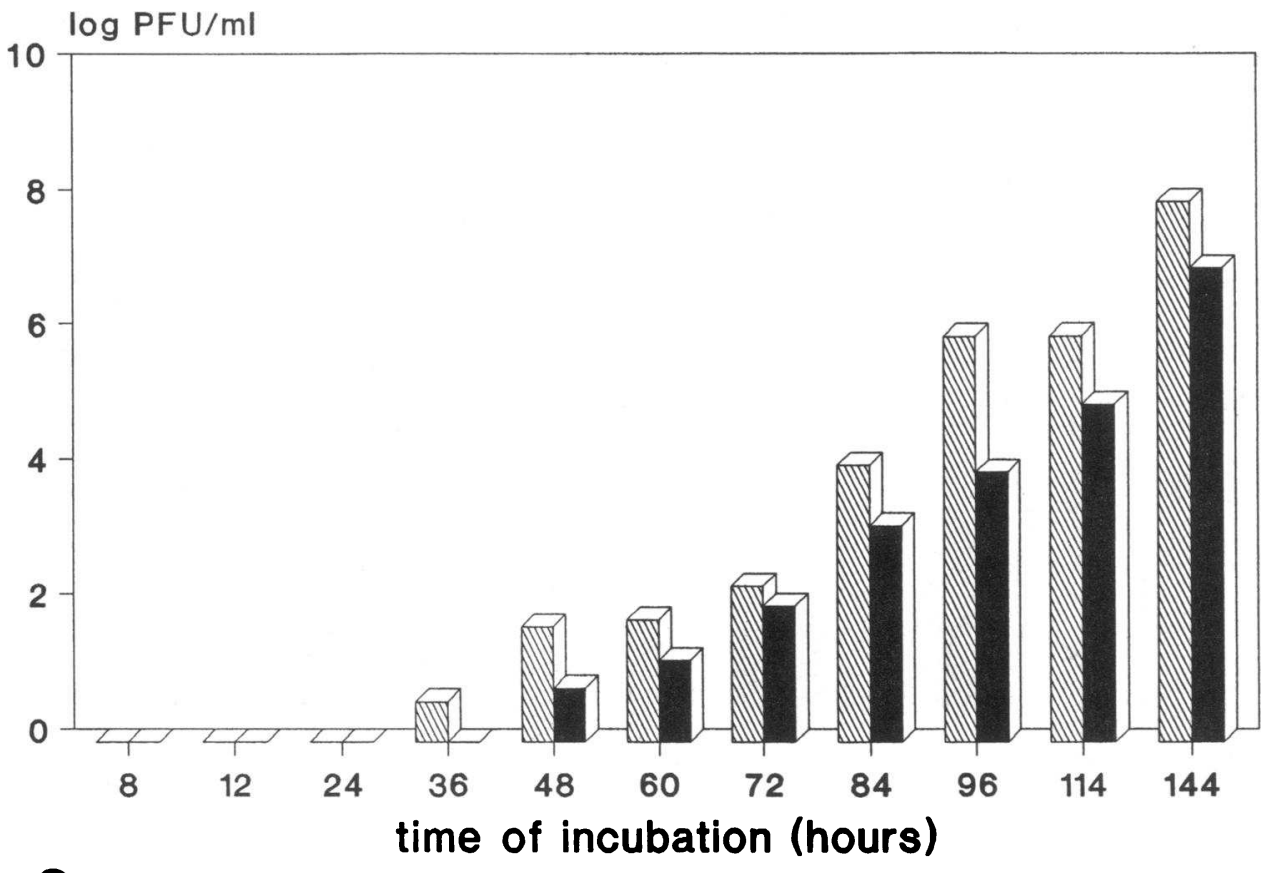

a
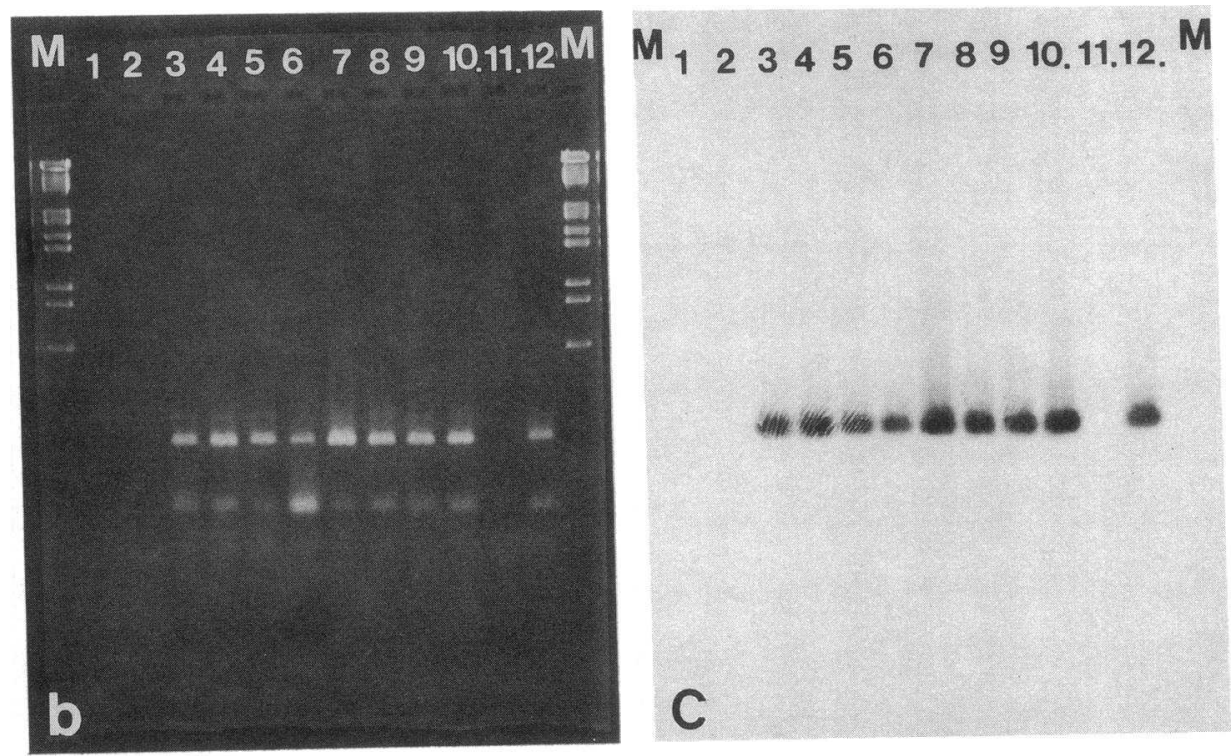

Figure 5. Release of infectious Marburg virus from infected endothelial cells. The infectivity of the budded virus particles has been determined by plaque assay $(a)$. Infectious virus particles released from infected endothelial cells can be first detected $48 \mathrm{~h}$ postinfection (black column). The titers of virus propagated in endothelial cells (black columns) are nearly identical to those obtained from infected E6 cells (hatched columns). Using RNA, PCR budded virus particles can already be identified in tissue culture supernatants of endothelial cells $12 \mathrm{~h}$ after infection ( $b$ and $c$, lane 3$)$. The amplified DNA products ( 236 base pairs) were analyzed on a $1 \%$ agarose gel and visualized by ethidium bromide staining $(b)$. The virus specificity of the amplified DNA products is demonstrated by Southern blot hybridization using a radiolabeled cDNA piece of the L gene of MBG (c). $\mathrm{M}$, molecular weight marker (lambda DNA/EcoRI and HindIII; Boehringer Mannheim); 1, control: $96 \mathrm{~h}$ postinfection (p.i.) without primers; 2,8 h p.i.; 3,12 h p.i.; 4, 24 h p.i.; 5,36 h p.i.; 6,48 h p.i.; 7, 60 h p.i.; 8,72 h p.i.; 9,84 h p.i.; 10, 96 h p.i.; 11, control: primers without RNA template; 12 , control: purified MBG vRNA. used in cell culture preparation. Organ cultures were infected as described for the tissue culture system, incubated for four and six days, and then prepared for electron microscopy. Prior to infection, the integrity of the endothelium was checked by cryostat sections and conventional toluidine blue staining. Examination of several thin sections at days 4 and 6 postinfection demonstrated budded virions from multiple infected endothelial cells over the entire endothelium. Budding occurred from the apical and the basal surface without any marked differences in quantity (Figs. $6 a$ and $b$ ). Partial endothelial lysis occurred and was indicated by cell debris associated viruses $(c)$. Virion particles did not differ in morphology from particles budded from E6 cells or cultured HUVEC. In addition plaque assay and RNA PCR of organ culture-derived supernatant showed that infectious virus was released.

\section{Discussion}

To better understand the pathogenesis of the severe shock syndrome and fulminating hemorrhage in MBG disease we examined viral replication in human endothelial cells. It is generally accepted that shock development is associated with a loss of the integrity of the endothelium by destruction and increased vascular permeability. In MBG disease this can be caused by several mechanisms $(a)$ endothelial cell lysis by direct virus replication, $(b)$ massive release of inflammatory mediators by unspecific (e.g., phagocytosis) or specific (e.g., virus replication) activation of inflammatory cells, and $(c)$ oxidant injury or unspecific immune response as discussed previously (25). We examined the replication of MBG, strain Musoke, in primary endothelial cell cultures prepared from human umbilical cord vein and in organ cultures of human umbilical cord vein. 

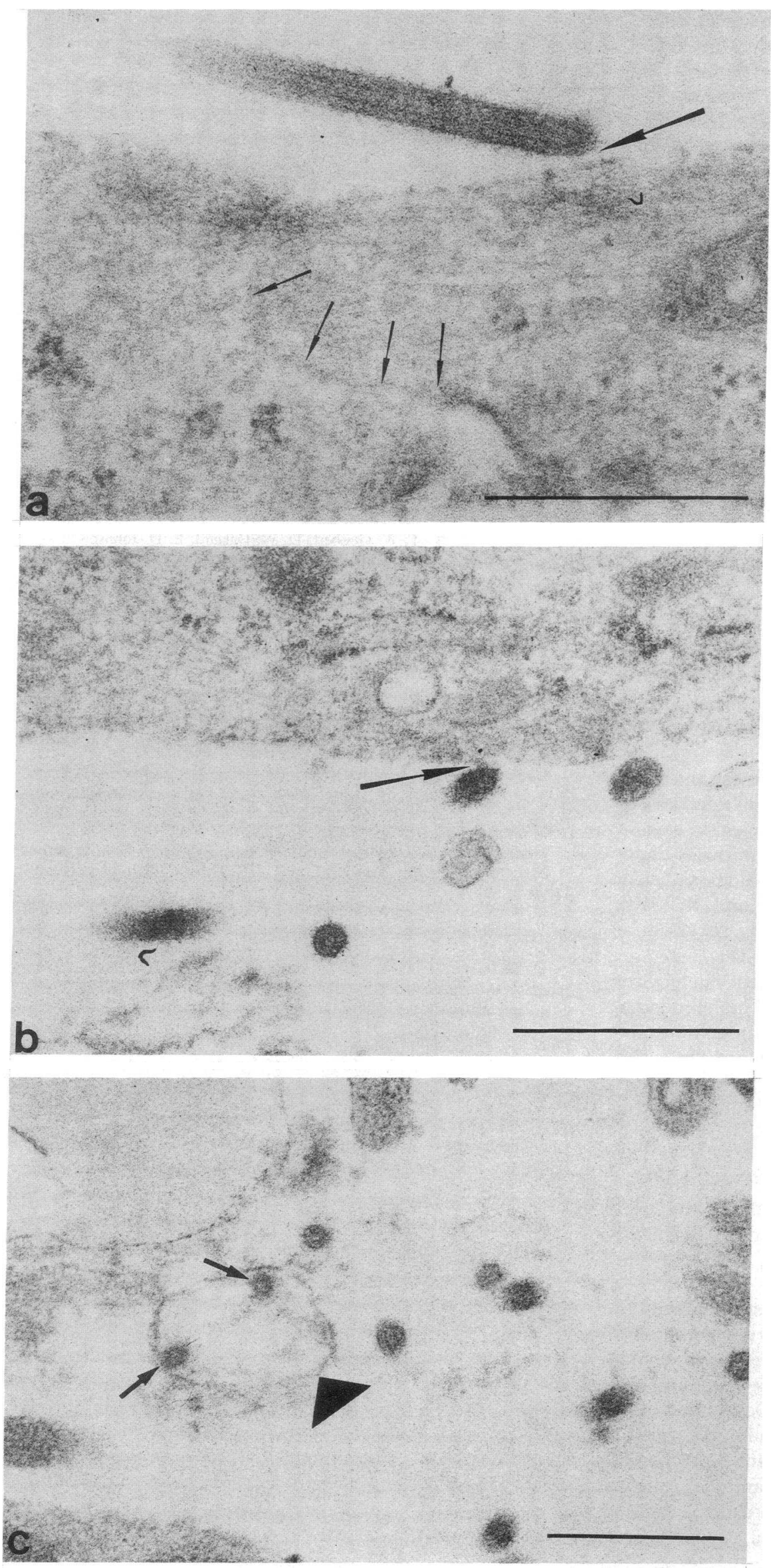

Figure 6. Transmission electron microscopy of organ-cultured pieces of human umbilical cord veins infected with Marburg virus. Virion particles bud from the apical $(a)$ as well as the basolateral $(b)$ plasma membrane of infected endothelial cells. Plasma bridges connecting viral particles with the plasma membrane of endothelial cells are obvious ( $a$ and $b$, arrows). Intercellular junctions are indicated by small arrows $(a)$. Mature viral particles ( $c$, arrows) associated with cell debris ( $c$, arrowhead) are seen in the surrounding of destructed endothelial cells $(c)$. Bars, $0.5 \mu \mathrm{m}$. 
We demonstrate here that MBG replicates in human endothelial cells and that the course of infection does not differ significantly from infection of cultured E6 cells (monkey kidney cells), which are commonly used for in vitro virus propagation. Early in infection numerous areas with localized cell damage were obviously followed by a generalized damage of the endothelial cells late in infection. The budded virus is infectious, and virus titers obtained from infected human endothelial cells and E6 cells are comparable. Endothelial cells were also infected in a more physiological surrounding, i.e., in organ culture of whole veins. In both systems infection and replication could be shown by electron microscopy, RNA PCR, and plaque assay. Consequently, these findings clearly demonstrate that the endothelial cell is a suitable target for Marburg virus replication.

The endothelial cell, which functions as the barrier between the blood and the surrounding tissue, is a strategically important cell type for virus spread in the infected host. Two reasons may be important: first, virus replication in endothelial cells could help to maintain and reinforce the viremic phase. This assumption is supported by the fact that virus budding occurred to a significant degree from the apical plasma membrane. On the other hand, basolateral budding would allow viruses to spread into the tissues even early in infection. Second, viral replication may lead to destruction of endothelial cells with a loss of their barrier function and virus spread into the tissues. This is in line with our observation of a generalized virus-induced endothelial cell destruction in cell and organ cultures and also supported by observations made in filovirus-infected animals (25).

If one considers the results obtained from the cell and organ culture experiments, a destruction of endothelial cells as a primary result of viral replication would be sufficient to explain the onset of a severe shock syndrome and hemorrhage. Endothelial cell destruction later on in infection would be sufficient to start a disseminated intravascular coagulation (DIC) with consumption of coagulation factors as initially discussed for filovirus infections of several severe cases $(25,31)$.

In addition, the onset of the bleeding tendency in filovirus disease is supported by the loss of the integrity of the endothelium as could be demonstrated in vitro (organ culture) and observed in infected animals (25). The hemorrhage occurs later on in infection due to the fact that first a localized destruction of the endothelium appears. These defects are covered by the spread of surrounding intact endothelial cells (small wound-healing mechanism) as demonstrated in vitro (32). Following an extended damage of the endothelium caused by virus replication, this repair mechanism fails and red blood cells penetrate into the underlining tissues. The bleeding tendency is reinforced by a decrease of the bloodstream, which is a common consequence of shock syndromes.

In conclusion, endothelial cells are fully susceptible to infection and replication of $\mathrm{MBG}$ and thus may play a key role in the development of MBG hemorrhagic disease. Our data indicate that endothelial cells serve as a sufficient target for MBG replication even in the infected organism. Destruction of the endothelium caused by viral replication could propagate the development of the shock syndrome and fulminating hemorrhage. Appropriate studies on MBG-infected animals are necessary to show that our in vitro data are in accordance with the in vivo situation in the infected host. In general, endothelial cell lysis caused by virus replication should be discussed as a major event for the development of virus-induced hemorrhagic diseases.

\section{Acknowledgments}

The extraordinary technical assistance by Heike Wiener is greatly acknowledged.

This work was supported by the Deutsche Forschungsgemeinschaft and performed in cooperation between projects A6 and B1 of the Sonderforschungsbereich 286 .

\section{References}

1. Martini, G. A. 1971. Marburg virus disease. Clinical syndrome. In Marburg Virus Disease. G. A. Martini and R. Siegert, editors. Springer, New York. 1-9.

2. Smith, C. E. G., D. I. H. Simpson, and E. T. W. Bowen. 1967. Fatal human disease from vervet monkeys. Lancet ii:1119-1121.

3. Kiley, M. P., E. T. W. Bowen, G. A. Eddy, M. Isaäcson, K. M. Johnson, J. B. McCormick, F. A. Murphy, S. R. Pattyn, D. Peters, O. W. Prozesky, R. L. Regnery, D. I. H. Simpson, W. Slenczka, P. Sureau, G. van der Groen, P. A. Webb, and H. Wulff. 1982. Filoviridae: a taxonomic home for Marburg and Ebola viruses? Intervirology. 18:24-32.

4. Jahrling, R. B., T. W. Geisbert, D. W. Dalgard, E. D. Johnson, T. G. Ksiazek, W. C. Hall, and C. J. Peters. 1990. Preliminary report: isolation of Ebola virus from monkeys imported to USA. Lancet. 335:502-505.

5. Murphy, F. A., M. P. Kiley, and S. P. Fisher-Hoch. 1990. FiloviridaeMarburg and Ebola viruses. In Virology. B. N. Fields and D. M. Knipe, editors. Raven Press, New York. 933-942.

6. Martini, G. A., and R. Siegert. 1971. Marburg Virus Disease. Springer, New York. $230 \mathrm{pp}$

7. Gear, J. S. S., G. A. Cassel, A. J. Gear, B. Trappler, L. Clausen, A. M. Meyers, M. C. Kew, T. H. Bothwell, R. Sher, G. B. Miller, J. Schneider, H. J. Koornhoff, E. D. Comperts, M. Isaäcson, and J. H. S. Gear. 1975. Outbreak of Marburg virus disease in Johannesburg. Br. Med. J. 4:489-493.

8. Kiley, M. P., N. J. Cox, L. H. Elliott, A. Sanchez, R. DeFries, M. J. Buchmeier, D. D. Richman, and J. B. McCormick. 1988. Physicochemical properties of Marburg virus: evidence for three distinct strains and their relationship to Ebola virus. J. Gen. Virol. 69:1957-1967.

9. Smith, D. H., B. K. Johnson, M. Isaäcson, R. Swanapoel, K. M. Johnson, M. P. Kiley, A. Bagshawe, T. Siongok, and W. K. Keruga. 1982. Marburg virus disease in Kenya. Lancet. i:816-820.

10. ICTV. 1990. The order Mononegavirales. Paramyxovirus Study Group of the Vertebrate Subcommittee. Virology Division News. Arch. of Virol. 117:137140.

11. Feldmann, H., E. Mühlberger, A. Randolf, C. Will, M. P. Kiley, A. Sanchez, and H.-D. Klenk. 1992. Marburg virus, a filovirus: messenger RNAs, gene order, and regulatory elements of the replication cycle. Virus Res. 24:1-19.

12. Regnery, R. L., K. M. Johnson, and M. P. Kiley. 1981. Marburg and Ebola viruses: possible members of a new group of negative strand viruses. In The Replication of Negative Strand Viruses. D. H. L. Bishop and R. W. Compans, editors. Elsevier/North-Holland, New York. 971-977.

13. Elliott, L. H., M. P. Kiley, and J. B. McCormick. 1985. Descriptive analysis of Ebola virus proteins. Virology. 163:169-176.

14. Feldmann, H., C. Will, M. Schikore, W. Slenczka, and H.-D. Klenk. 1991. Glycosylation and oligomerization of the spike protein of Marburg virus. Virology. 182:353-356.

15. Mühlberger, E., A. Sanchez, A. Randolf, C. Will, M. P. Kiley, H.-D Klenk, and H. Feldmann. 1992. The nucleotide sequence of the $L$ gene of Marburg virus, a filovirus: homologies with paramyxoviruses and rhabdoviruses. $\mathrm{Vi}$ rology. 187:534-547.

16. Sanchez, A., M. P. Kiley, H.-D. Klenk, and H. Feldmann. 1992. Sequence analysis of the Marburg virus nucleoprotein gene: comparison to Ebola virus and other nonsegmented negative-strand RNA viruses. J. Gen. Virol. 73:347-357.

17. Johnson, K. M., J. V. Lang, P. A. Webb, and F. A. Murphy. 1977. Isolation and partial characterization of a new virus causing acute hemorrhagic fever in Zaire. Lancet. i:569-571.

18. Ishak, K. G., D. H. Walker, J. A. W. Coetzer, J. J. Gardner, and L. Forelkin. 1982. Viral haemorrhagic fevers with hepatic involvement: pathologic aspect with clinical correlations. Prog. Liver Dis. 3:495-515.

19. Crone, C. 1987. The malpighi lecture. From 'Porositates carnis' to cellular microcirculation. Int. J. Microcirc. Clin. Exp. 6:101-122.

20. Majno, G., and G. Palade. 1961. Studies on inflammation I. The effect of histamine and serotonin on vascular permeability, an electron microscopic study. J. Biophys. Biochem. Cytol. 11:571-605. 
21. Michel, C. C. 1988 . Capillary permeability and how it may change. $J$. Physiol. CAMB. 404:1-29.

22. Schnittler, H.-J., A. Wilke, T. Gress, N. Suttorp, and D. Drenckhahn 1990. Role of actin and myosin in the control of paracellular permeability in pig rat, and human vascular endothelium. J. Physiol. CAMB. 431:379-401.

23. Bachofen, M., and E. R. Weibel. 1974. Basic pattern of tissue repair in human lungs following unspecific injury. Chest. 65:14-19.

24. Trump, B. F., J. M. Valigorsky, R. T. Jones, W. J. Mergner, J. H. Garcia and R. A. Cowley. 1975. The application of electron microscopy and cellula biochemistry to the autopsy. Observations on cellular changes in human shock. Hum. Pathol. 6:499-516.

25. Fisher-Hoch, S. P., G. S. Platt, G. H. Neild, T. Southee, A. Baskerville, R. T. Raymond, G. Lloyd, and D. I. H. Simpson. 1985. Pathophysiology of shock and hemorrhage in a fulminating viral infection (Ebola). J. Infect. Dis. 152:887894.

26. Becker, S., H. Feldmann, C. Will, and W. Slenczka. 1992. Evidence for occurrence of filovirus antibodies in humans and imported monkeys: do subclinical filovirus infections occur worldwide? Med. Microbiol. Immunol. 181:43-55.
27. Maniatis, T., E. F. Fritsch, and J. Sambrook. 1989. Molecular Cloning: A Laboratory Manual. Cold Spring Harbor Laboratory, Cold Spring Harbor, NY. Book 2: 9.31-9.57.

28. Hoyer, L. W., R. P. De Los Santos, and J. R. Hoyer. 1973. Antihemophilic factor antigen. Localization in endothelial cells by immunofluorescent microscopy. J. Clin. Invest. 52:2737-2744.

29. Wagner, D. D., J. B. Olmsted, V. J. Marder. 1982. Immunolocalization of von Willebrand protein in Weibel-Palade bodies of human endothelial cells. $J$. Cell Biol. 95:355-360.

30. Peters, D., G. Müller, and W. Slenczka. 1971. Morphology, development, and classification of Marburg virus. In Marburg Virus Disease. G. A. Martini and R. Siegert, editors. Springer, New York. 68-83.

31. Verstraete, M. 1978. Disseminated intravascular coagulation. In Ebola Virus Hemorrhagic fever. S. R. Pattyn, editor. Elsevier/North Holland, Amsterdam. 225-235.

32. Wong, M. K. K., and A. I. Gotlieb. 1988. The reorganization of microfilaments, centrosomes, and microtubules during in vitro small wound reendothelialization. J. Cell Biol. 107:1777-1783. 